\title{
Fatigue behaviour FEM modeling of deep groove ball bearing mounted in automotive alternator submitted to variable loading
}

\author{
Ayao. E. Azianou ${ }^{1,2, a}$, Karl Debray ${ }^{1}$, Fabrice Bolaers ${ }^{1}$, Philippe Chiozzi $^{2}$ and Frédéric Palleschi ${ }^{2}$ \\ ${ }^{1}$ GRESPI, Université de Reims Champagne Ardenne, EA 4694 URCA, Moulin de la Housse, \\ 51687 Reims Cedex 2, France \\ ${ }^{2}$ Valeo Electric Systems, 2 rue André boulle, 94000 Créteil, France
}

\begin{abstract}
Ball bearings subsurface materials are subjected to rolling contact fatigue with multiaxial stress state during loading cycle. The complex operating conditions of automotive bearings are different from classic operating conditions their fatigue crack initiation predicted by standards can be seen underestimated. This work presents a numerical approach of ball bearings to evaluate its fatigue behaviour in order to predict the life. A preliminary study has been done to evaluate the load distribution in the bearings. The results are integrated in a numerical dynamic model to study the bearing material rolling fatigue behaviour in constant and variable loading cases. By using fatigue criteria and damage laws, the analysis of stress state in bearing material leads to life prediction or the number of cycles before crack initiations. These results are compared to current standard methods used for ball bearing life prediction.
\end{abstract}

\section{Material and methods}

Ball bearings are important components in machinery and their fatigue behaviour study are necessary during mechanisms design especially in automotive. The demands for new generations of alternators require bearings that can survive under severe operating conditions. Some examples of these conditions are frequent stoppings and engine acyclisms that lead to random load variations on ball bearings in the alternators and generates their life modification. Standards based on probabilistic model by Lundberg and Palmgren [1] and other works that are used to predict bearing failure can be seen insufficient when bearings are subjected to some particular conditions. This work proposed a numerical approach for the fatigue life prediction ball bearings submitted to variable load.

A bearing is a complex system consisting of inner and outer rings and balls rolling on the raceway. Model the fatigue behaviour of ball needs to know stress on the surface and subsurface of the raceway. A previous quasi-static analysis [2] has been done to get the load distribution in the bearing. Thanks to this analysis, we can know the load on a ball in any position on the raceway. From load distribution, a dynamic bearing Finite Element model was developed on Abaqus to get the time dependent stress state. To save computation time, the deep groove ball bearing is reduced to a simplified model consisting of

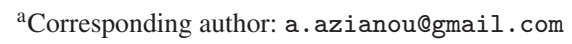

This is an Open Access article distributed under the terms of the Creative Commons Attribution License 4.0, which permits unrestricted use, distribution, and reproduction in any medium, provided the original work is properly cited. 


\section{MATEC Web of Conferences}
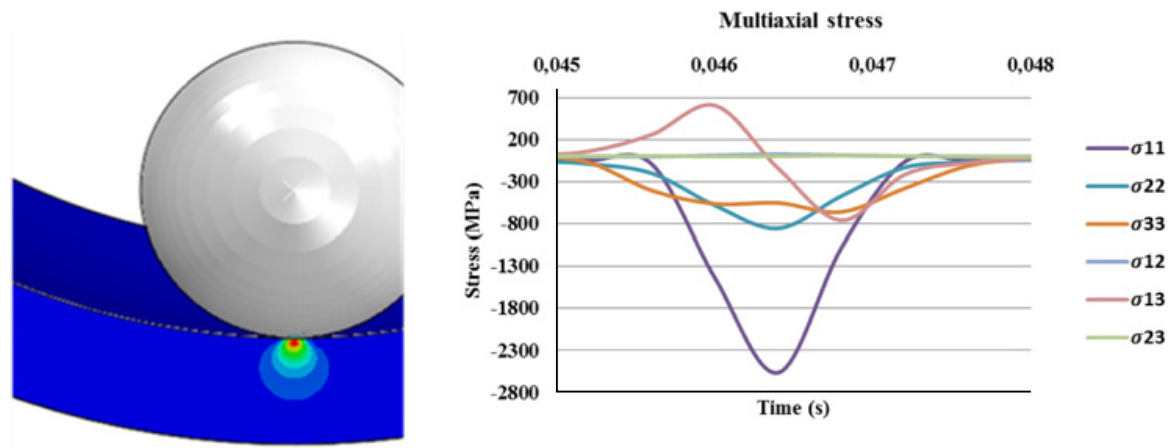

Figure 1. Multiaxial stress in the subsurface of raceway of ball bearing.

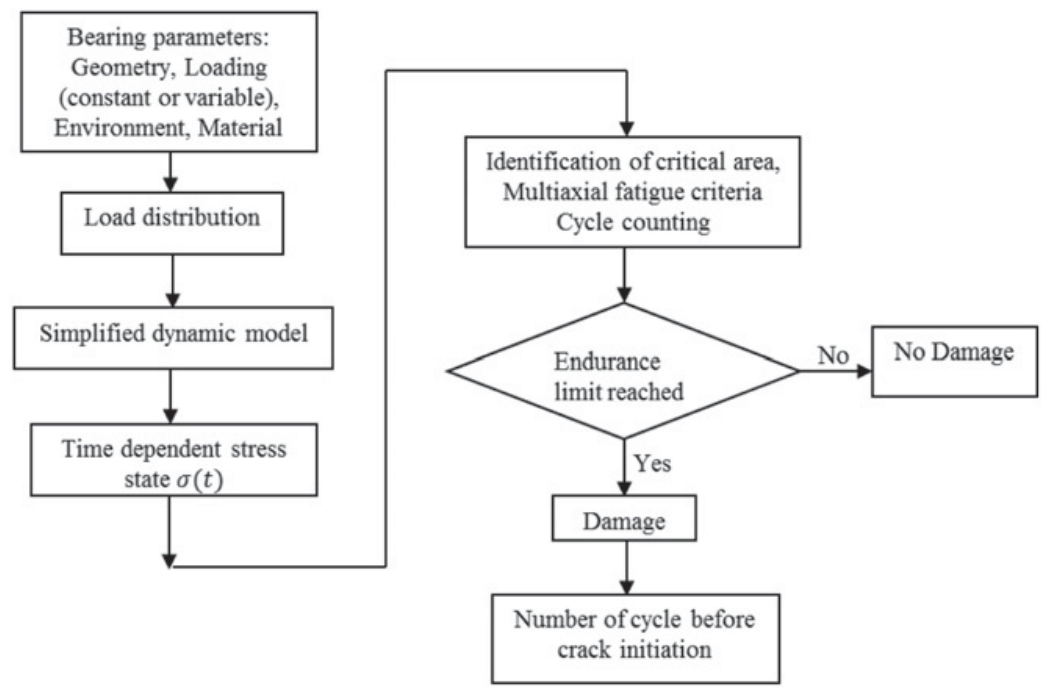

Figure 2. The fatigue analysis steps of ball bearing.

a ball rolling on the raceway of a part of a ring submitted to unfavourable conditions; in the case of fixed outer ring, it is a part of outer ring. The analysis reveals multiaxial time dependent stress in the subsurface of the raceway (Fig. 1). A multiaxial fatigue criterion was used to indicate if the material endurance is exceeded. Fatigue analysis using Stress-life curve predicts the number of cycles before the subsurface crack initiates for constant and variable loads. Figure 2 presents the steps of fatigue analysis. Results in the case of radial constant and variable loading are compared to standard methods of crack initiation prediction.

\section{References}

[1] Lundberg G., and Palmgren A.,"Dynamic capacity of rolling bearings", Acta Polytechnica, Mechanical Engineering series 2, 1, n 3, 7 (1947)

[2] Azianou, A. E., Debray, K., Bolaers, F., Chiozzi, P., \& Palleschi, Modeling of the Behavior of a Deep Groove Ball Bearing in Its Housing. Journal of Applied Mathematics and Physics, 1, 45 (2013) 